\title{
A Pipeline with Multiplex Reverse Transcription Polymerase Chain Reaction and Microarray for Screening of Chromosomal Translocations in Leukemia
}

\author{
Fei-Fei Xiong, ${ }^{1,2}$ Ben-Shang Li, ${ }^{3}$ Chun-Xiu Zhang, ${ }^{2}$ Hui Xiong, \\ Shu-Hong Shen, ${ }^{3}$ and Qing-Hua Zhang ${ }^{1,4,5}$ \\ ${ }^{1}$ School of Life Science and Technology, Tongji University, Shanghai 200092, China \\ ${ }^{2}$ National Engineering Research Center for Biochip at Shanghai, Shanghai 201203, China \\ ${ }^{3}$ Department of Hematology and Oncology, Shanghai Children's Medical Center, \\ Shanghai Jiaotong University School of Medicine, Shanghai 200127, China \\ ${ }^{4}$ State Key Laboratory of Medical Genomics and Shanghai Institute of Hematology, Ruijin Hospital, \\ Shanghai Jiaotong University School of Medicine, Shanghai 200025, China \\ ${ }^{5}$ Wayen Biotechnologies Inc., Shanghai 201203, China
}

Correspondence should be addressed to Shu-Hong Shen; sshfranks@gmail.com and Qing-Hua Zhang; qhzhang@wayenbio.com Received 21 May 2013; Revised 1 August 2013; Accepted 19 August 2013

Academic Editor: Luca Arcaini

Copyright (c) 2013 Fei-Fei Xiong et al. This is an open access article distributed under the Creative Commons Attribution License, which permits unrestricted use, distribution, and reproduction in any medium, provided the original work is properly cited.

\begin{abstract}
Chromosome rearrangements and fusion genes present major portion of leukemogenesis and contribute to leukemic subtypes. It is practical and helpful to detect the fusion genes in clinic diagnosis of leukemia. Present application of reverse transcription polymerase chain reaction (RT-PCR) method to detect the fusion gene transcripts is effective, but time- and labor-consuming. To set up a simple and rapid system, we established a method that combined multiplex RT-PCR and microarray. We selected 15 clinically most frequently observed chromosomal rearrangements generating more than 50 fusion gene variants. Chimeric reverse primers and chimeric PCR primers containing both gene-specific and universal sequences were applied in the procedure of multiplex RTPCR, and then the PCR products hybridized with a designed microarray. With this approach, among 200 clinic samples, 63 samples were detected to have gene rearrangements. All the detected fusion genes positive and negative were validated with RT-PCR and Sanger sequencing. Our data suggested that the RT-PCR-microarray pipeline could screen 15 partner gene pairs simultaneously at the same accuracy of the fusion gene detection with regular RT-PCR. The pipeline showed effectiveness in multiple fusion genes screening in clinic samples.
\end{abstract}

\section{Introduction}

Myeloid neoplasms and acute leukemia encompass many different clinical and pathological entities, some with unique genetic features and reflection on risk-stratification and appropriate therapy strategies. According to the World Health Organization (WHO) 2008 classification [1, 2], acute myelogeneous leukemia (AML), acute lymphoblastic leukemia (ALL), and chronic myelogenous leukemia $(\mathrm{CML})$ are categorized by the presence of specific balanced chromosomal translocations: AML is associated with $\mathrm{t}(8 ; 21)(\mathrm{q} 22 ; \mathrm{q} 22)$, inv(16)(p13q22) or $\mathrm{t}(16 ; 16)(\mathrm{p} 13 ; \mathrm{q} 22)$, $\mathrm{t}(15 ; 17)(\mathrm{q} 22 ; \mathrm{q} 12)$, and $11 \mathrm{q} 23 / M L L$ abnormalities; ALL is mainly associated with $\mathrm{t}(12 ; 21)(\mathrm{p} 13 ; \mathrm{q} 22), \mathrm{t}(9 ; 22)(\mathrm{q} 34 ; \mathrm{q} 11.2)$, and $\mathrm{t}(1 ; 19)(\mathrm{q} 23 ; \mathrm{p} 13)$; and $\mathrm{CML}$ is characterized by the $\mathrm{Ph}+$ chromosome or $\mathrm{t}(9 ; 22)(\mathrm{q} 34 ; \mathrm{q} 11.2)$. It can be said that the translocations above cover approximately $40-50 \%$ of childhood and adult AML and ALL and $90-95 \%$ of CML patients [3-6].

PCR method, especially reverse transcription-PCR (RTPCR), nowadays has been shown to be a sensitive tool in the clinical evaluation of leukemia. As there are many distinct genetic alterations in various leukemia subtypes, it would be extremely labor intensive to evaluate specific fusions via a panel of individual monoplex assays. This can be avoided by the use of multiplex RT-PCR assays with various downstream 
detection methods, such as gel-based techniques and bead array [7-10]. Microarray is another useful detection assay. Two biochip-based diagnostic systems were reported: a gelbased biochip by Nasedkina et al. [11,12] and MLLFusionChip and $A M L F u s i o n C h i p$ from France $[13,14]$. In these previous works, the gel-based biochip only targeted 7 chromosomal translocations, addressing 13 fusion variants in sum, while other two chips covered certain leukemia group. That was far from translocation types needed for the initial screening stage. In addition, the procedure of PCR was very complicated, with at least two parallel nested multiplex reactions. Therefore, we planned to make RT-PCR-microarray assay much easier, hoping to detect the frequently occurring and well-defined translocations in leukemia.

In our study, we described (a) the improvement of multiplex RT-PCR in combination with microarrays analysis system that facilitated the simultaneous detection of 15 chromosomal aberrations, including more than 50 mRNA splice variants with prognostic value; (b) the sensitivity level of each fusion gene in cell lines or clinical patients unique translocations; (c) the application of this method to test 200 leukemia clinical patients; and (d) the potential diagnostic value of this procedure for detection of unusual fusion genes or fusion junctions.

\section{Material and Methods}

2.1. Cell Lines and Patient Samples. The 15 chromosomal translocations studied and the GenBank database references for the genes involved were given in Table 1. Cell lines and some patient samples with unique translocations as positive controls were also used in the study. The leukemic cell line HL-60 served as a negative control. Cells were maintained in RPMI 1640 (Gibco, Grand Island, NY, USA) supplemented with $10 \%$ fetal bovine serum (Gibco). Meanwhile, we also constructed fusion fraction RNAs for translocations (e.g., PLZF-RARA, NPM1-RARA, CBFB-MYH11 type D, SIL$T A L 1$, and $B C R-A B L \mathrm{p} 230)$ that had neither cell lines nor positive samples. We constructed expression plasmids using pcDNA3.0 vector (Invitrogen, Carlsbad, CA, USA), then transfected the constructed expression plasmids into $293 \mathrm{~T}$ cells using Lipofectamine 2000 (Invitrogen), and finally collected cells in TRIzol (Invitrogen) $48 \mathrm{~h}$ after transfection.

200 bone marrow samples of ALL, AML, and CML patients were also used in this work for clinical screening. They were received from the Department of Hematology of Shanghai Children's Medical Center (Shanghai, China), Ruijin Hospital (Shanghai, China), and Changhai Hospital (Shanghai, China).

2.2. RNA Preparation. Leukemia cell extract was prepared by the TRIzol (Invitrogen) homogenization method according to the manufacturer's recommendations. Total RNA was resuspended in RNase-free water, and its concentration and quality were determined by NanoDrop ND-1000 Spectrophotometer (NanoDrop Technologies, Wilmington, DE, USA) and by $2 \%$ agarose gel electrophoresis. Then the RNA was stored at $-80^{\circ} \mathrm{C}$.
2.3. Multiplex RT-PCR Primers. We planned to use only one multiplex RT-PCR reaction to detect more than 50 fusion gene variants of 15 chromosomal rearrangements. To reduce the number of primers used in multiple PCR, we designed chimeric forward primers and chimeric reverse primers containing both gene-specific and universal sequences.

The gene-specific portions of the chimeric forward primers for fusion genes in leukemia were designed or modified with the primer analysis software Primer Premier 5.0 (Premier Biosoft International, Palo Alto, CA, USA), based on sequence data of fusion partner genes deposited in GenBank database or from publications [7] (Table 2). We added bacteriophage promoter T7 and SP6 to the $5^{\prime}$ end of the PCR amplifying forward and reverse primers, respectively, as the universal parts. Thus in the first reverse transcription step, the synthesized cDNAs could be linked to SP6 sequence at their $5^{\prime}$ end, so that only one reverse universal primer SP6 was required in the following multiple PCR step. In addition, the universal primer, SP6, was $5^{\prime}$-labeled with biotin so that amplicons could be analyzed with microarrays (Figure 2). We applied GUS gene (beta-glucuronidase, M15182) [15] as internal positive control to avoid false-negative results cased by varying RNA quality and handling errors. Oligonucleotide primers were provided by Generay Biotechnology (Shanghai, China).

2.4. Microarray Probes. Oligonucleotide probes for translocations in leukemia were designed with the primer analysis software Primer Premier 5.0 (Premier Biosoft International), based on cDNA sequences deposited in GenBank. We designed 29 chimeric junction probes for each splice variant already known for fusion gene transcripts of interest, except the $M L L$ rearrangements. In addition, 20 unique probes for each fusion genes partner were selected as positive controls in each gene fusion event, which located upstream or downstream of the described breakpoint. This microarray also included one probe for the GUS gene served as an internal positive control for the quality of DNA target prepared for hybridization. The sequences of probes were shown in Table 3. All probes were included in triplicate. The probes were 20-30 nucleotides (nt) long, and their specificity and sensitivity were tested by positive samples to ensure the accuracy of the microarray. The probes and biotinylated control probes were spotted onto CapitalBio optical grade aldehyde slides (CapitalBio Corporation, Beijing, China) (Figure 1). Oligonucleotide probes were synthesized in Sangon Biotech (Shanghai, China).

2.5. Multiplex RT-PCR. Multiplex RT-PCR was carried out in two steps. For the reverse transcription step, $2 \mu \mathrm{g}$ of total RNA was incubated at $70^{\circ} \mathrm{C}$ for $5 \mathrm{~min}$ with a mixture of the chimeric reverse primers ( 3 pmol of each) and then reverse-transcribed at $42^{\circ} \mathrm{C}$ for $1 \mathrm{~h}$ in a total volume of $25 \mu \mathrm{L}$ containing $200 \mathrm{U}$ M-MLV reverse transcriptase (Promega, Madison, WI, USA), 25 U RNasin Ribonuclease Inhibitor (Promega), $1 \mathrm{mM}$ of each dNTP, $10 \mathrm{mM}$ dithiothreitol, $50 \mathrm{mM}$ Tris- $\mathrm{HCl}, \mathrm{pH} 8.3,75 \mathrm{mM} \mathrm{KCl}$, and $3 \mathrm{mM} \mathrm{MgCl}_{2}$. Then 
TABLE 1: Chromosomal alterations included in the multiplex RT-PCR analysis.

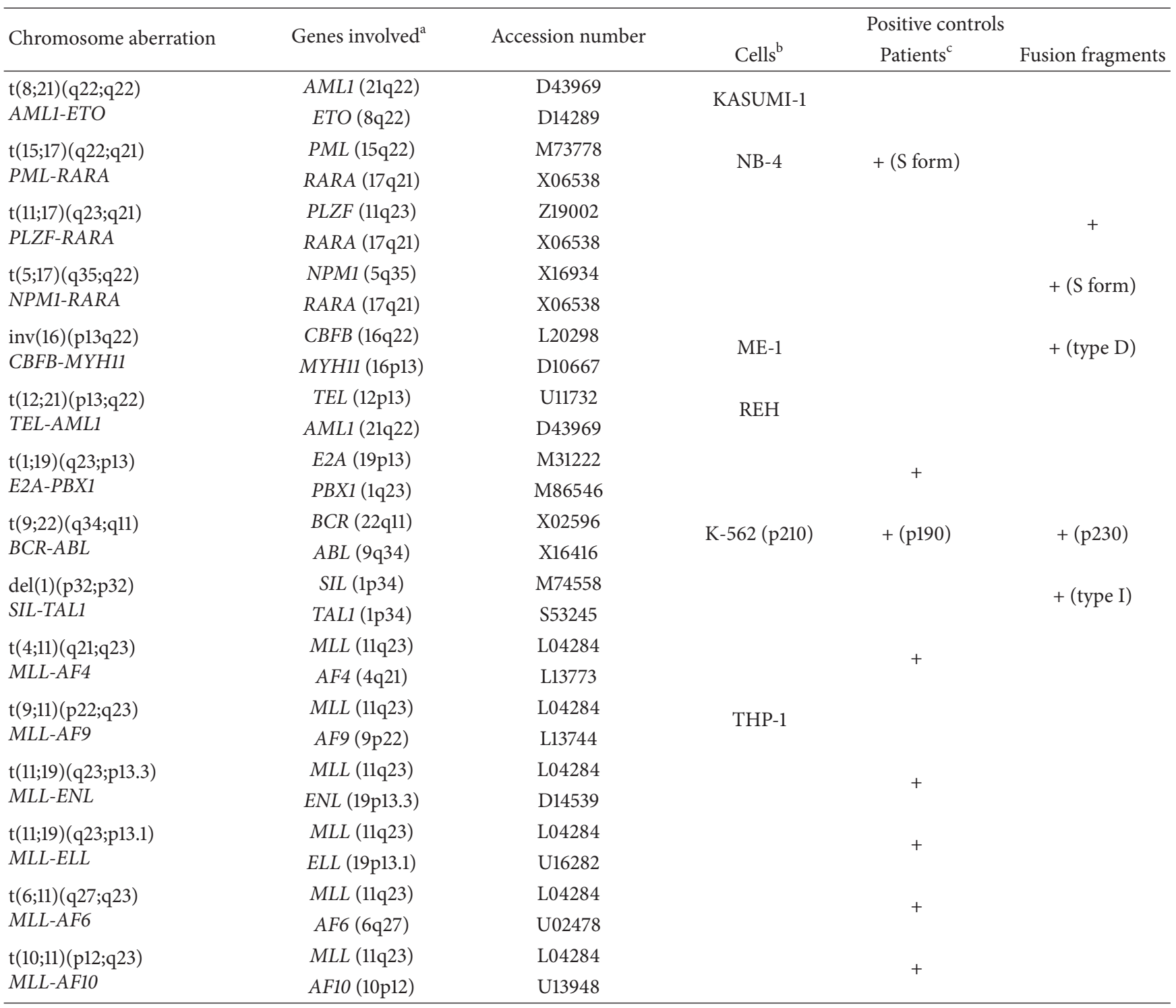

${ }^{a}$ Chromosomes on which genes are located are in brackets.

${ }^{\mathrm{b}}$ Cells were kindly provided by Ruijin Hospital (Shanghai, China).

${ }^{c}$ Patients RNAs were kindly provided by Shanghai Children's Medical Center (Shanghai, China).

the cDNA reaction mixture was heated at $70^{\circ} \mathrm{C} 15 \mathrm{~min}$ to inactivate reverse transcriptase.

For the PCR step, a two-round PCR amplification was carried out. $1 \mu \mathrm{L}$ cDNA reaction mixture was added to $20 \mu \mathrm{L}$ of multiplex mixture containing a mixture of chimeric PCR primers (3 pmol of each), 4 pmol the universal primer SP6, $11 \mathrm{mM}$ Tris- $\mathrm{HCl}, \mathrm{pH} 8.3,55 \mathrm{mM} \mathrm{KCl}, 1.5 \mathrm{mM} \mathrm{MgCl}_{2}, 15 \%$ DMSO, $0.4 \mathrm{mM}$ each of dNTPs, and $1.25 \mathrm{U}$ of ExTaq HS polymerase (Takara, Dalian, LN, China). PCR cycles included 30 cycles of $95^{\circ} \mathrm{C}$ for $30 \mathrm{~s}, 55^{\circ} \mathrm{C}$ for 40 seconds, $72^{\circ} \mathrm{C}$ for $1 \mathrm{~min}$, and finally $72^{\circ} \mathrm{C}$ for 7 minutes. After the first PCR, $1 \mathrm{uL}$ of the first round product was added to $20 \mathrm{uL}$ secondround multiplex mixtures that contained $10 \mathrm{mM}$ Tris- $\mathrm{HCl}$, $\mathrm{pH} 8.3,50 \mathrm{mM} \mathrm{KCl}, 1.5 \mathrm{mM} \mathrm{MgCl}_{2}, 0.2 \mathrm{mM}$ of each dNTP, $0.4 \mathrm{pmol}$ of forward primers $\mathrm{T} 7$ and $4 \mathrm{pmol}$ of reverse primer
SP6 (labeled with biotin), and $1 \mathrm{U}$ of ExTaq HS polymerase (Takara). The second PCR consisted of 30 cycles of $95^{\circ} \mathrm{C}$ for $30 \mathrm{~s}, 50^{\circ} \mathrm{C}$ for 30 seconds, $72^{\circ} \mathrm{C}$ for $1 \mathrm{~min}$, and finally 7 minutes of extension at $72^{\circ} \mathrm{C} .3 \mu \mathrm{L}$ of the biotinylated-complexes was electrophoresed on an ethidium bromide stained $2 \%$ agarose gel. Negative controls without cDNA template were included for all PCR reaction mixtures.

2.6. Hybridization and Image Analysis. Microarray firstly was blocked in blocking buffer (2x SSC, $1 \mathrm{mg} / \mathrm{mL}$ BSA, $0.2 \%$ SDS) for $1 \mathrm{~h}$ at room temperature and then washed by pure water. Hybridization was performed in $25 \mu \mathrm{L}$ hybridization solution ( $5 \mathrm{x}$ SSPE, $0.1 \mathrm{mg} / \mathrm{mL}$ Salmon Sperm DNA, 0.5x Denhardt's solution, all from Invitrogen) and $20 \mu \mathrm{L}$ biotin labeled PCR products. Before hybridization, 
TABLE 2: Chimeric primers used in the multiplex RT-PCR.

\begin{tabular}{|c|c|c|}
\hline Primer name & Primer composition (size) ${ }^{\mathrm{a}}$ & Sequence $\left(5^{\prime}\right.$ to $\left.3^{\prime}\right)$ \\
\hline ETO_R & D14289_SP6_614 (18) & ATTTAGGTGACACTATAGA GAACTCTTTCTCCTATCT \\
\hline RARA_R & X06538_SP6_696 (16) & ATTTAGGTGACACTATAGA CGGTCGTTTCTCACAG \\
\hline MYH11-A_R & D10667_SP6_2271 (18) & ATTTAGGTGACACTATAGA TTGCGTAGCTGCTTGATG \\
\hline MYH11-DE_R & D10667_SP6_1374 (15) & ATTTAGGTGACACTATAGA GCAGGCTGTTCCGCT \\
\hline AML1_R & D43969_SP6_731 (17) & ATTTAGGTGACACTATAGA CACGGAGCAGAGGAAGT \\
\hline PBX1_R & M86546_SP6_657 (19) & ATTTAGGTGACACTATAGA TCGCAGGAGATTCATCACG \\
\hline TAL1_R & S53245_SP6_257 (15) & ATTTAGGTGACACTATAGA CGTCCCTCTAGCTGG \\
\hline ABL_R & X16416_SP6_576 (17) & ATTTAGGTGACACTATAGA AGCTGCCATTGATCCCG \\
\hline AF9_R & L13744_SP6_1910 (20) & ATTTAGGTGACACTATAGA TTCTTGATGCATCCAGTTGT \\
\hline ENL_R & D14539_SP6_301 (20) & ATTTAGGTGACACTATAGA GACCACCTTCTCCACGAAGT \\
\hline ELL_R & U16282_SP6_461 (17) & ATTTAGGTGACACTATAGA GTAGCGGCCTCCAGCCT \\
\hline AF6_R & U02478_SP6_360 (18) & ATTTAGGTGACACTATAGA AATCTGCCTTCCCGATCA \\
\hline AF10-A_R & U13948_SP6_2384 (19) & ATTTAGGTGACACTATAGA CACTGCCTCTCCAAAAGCT \\
\hline AF10-B_R & U13948_SP6_1146 (18) & ATTTAGGTGACACTATAGA TGACCTGAGCTGTGAGCT \\
\hline AF4_R & L13773_SP6_1674 (18) & ATTTAGGTGACACTATAGA TCGAGCATGGATGACGTT \\
\hline GUS_R & M15182_SP6_2057 (18) & ATTTAGGTGACACTATAGA TGCCGTGAACAGTCCAGG \\
\hline AML1_F & D43969_T7_903 (22) & TAATACGACTCACTATAGGGA CCAGGTTGCAAGATTTAATGAC \\
\hline PML-L_F & M73778_T7_1438 (19) & TAATACGACTCACTATAGGGA CAGTGTACGCCTTCTCCATCA \\
\hline PML-S_F & M73778_T7_927 (25) & TAATACGACTCACTATAGGGA GTGCGCCAGGTGGTAGCTC \\
\hline PLZF_F & Z19002_T7_1092(21) & TAATACGACTCACTATAGGGA CCACAAGGCTGACGCTGTATT \\
\hline NPM1_F & X16934_T7_160 (25) & TAATACGACTCACTATAGGGA ACGAAGGCAGTCCAATTAAAGTAAC \\
\hline CBFB_F & L20298_T7_267 (22) & TAATACGACTCACTATAGGGA TTTGAAGGCTCCCATGATTCTG \\
\hline TEL_F & U11732_T7_871 (23) & TAATACGACTCACTATAGGGA CACTCCGTGGATTTCAAACAGTC \\
\hline E2A_F & M31222_T7_1243 (22) & TAATACGACTCACTATAGGGA AAGATAGAAGACCACCTGGACG \\
\hline SIL_F & M74558_T7_24 (19) & TAATACGACTCACTATAGGGA CGACCCCAACGTCCCAGAG \\
\hline BCR-190_F & X02596_T7_1590 (20) & TAATACGACTCACTATAGGGA CGCTCTCCCTCGCAGAACT \\
\hline BCR-210_F & X02596_T7_2952 (24) & TAATACGACTCACTATAGGGA GAGTCACTGCTGCTGCTTATGTC \\
\hline BCR-230_F & X02596_T7_3682 (19) & TAATACGACTCACTATAGGGA CCAAGGTGCCCTACATCGT \\
\hline MLL_F & L04284_T7_3916 (20) & TAATACGACTCACTATAGGGA CCGCCTCAGCCACCTACTAC \\
\hline GUS_F & M15182_T7_1786 (20) & TAATACGACTCACTATAGGGA GGAATTTTGCCGATTTCATG \\
\hline T7 & & TAATACGACTCACTATAGGGA \\
\hline SP6 & & ATTTAGGTGACACTATAGA \\
\hline SP6-biotin & & biotin-ATTTAGGTGACACTATAGA \\
\hline
\end{tabular}

_R: reverse primer,_F: forward primer.

${ }^{a}$ Primer composition was given with gene accession number plus universal gene (T7 or SP6), the starting position on the gene, and total length in brackets.

the PCR product was treated with SAP (Takara) and ExoI (Takara) to eliminate primer dimers, then denatured at $94^{\circ} \mathrm{C}$, and briefly cooled on ice. Then the hybridization mixture was applied on the hybridization area covered with hybridization chamber (CapitalBio Corporation) and $12-14 \mathrm{~h}$ at $46^{\circ} \mathrm{C}$. After incubation, the slide was washed in washing solution A (2x SSC, 1\% SDS), washing solution B (1x SSC, $0.4 \%$ SDS), and washing solution C (0.6x SSC) for $5 \mathrm{~min}$ each, followed by incubation in Cy3-Streptavidin (SA) (Invitrogen) $1 \mathrm{~h}$ at room temperature. After washing, the fluorescence signal was detected on a GenePix 4000B scanner (Axon Instruments Inc., Union City, CA, USA) using $532 \mathrm{~nm}$ excitation. Data processing and image analysis were performed using GenePixPro6.0 software (Axon Instruments Inc.). When the averaged signal intensity from hybridization was higher than both two standard values, background value (negative samples and blank control plus $3 \mathrm{x}$ SD) and cutoff value (15\% of biotinylated control value), we considered the probe as true signal.

\section{Results}

3.1. Multiplex RT-PCR and Microarray Testing. Positive controls, including six cell lines, eight patient positive samples of known genotypes, and five constructed fusion fractions, were used to test primer pairs and reaction conditions in the multiplex PCR reactions (Figure 3 and Supplementary Figure 1 (see Supplementary Material available online at http://dx.doi.org/10.1155/2013/135086)). The correct sequence results confirmed that we had got right specific bands by multiplex RT-PCR. 


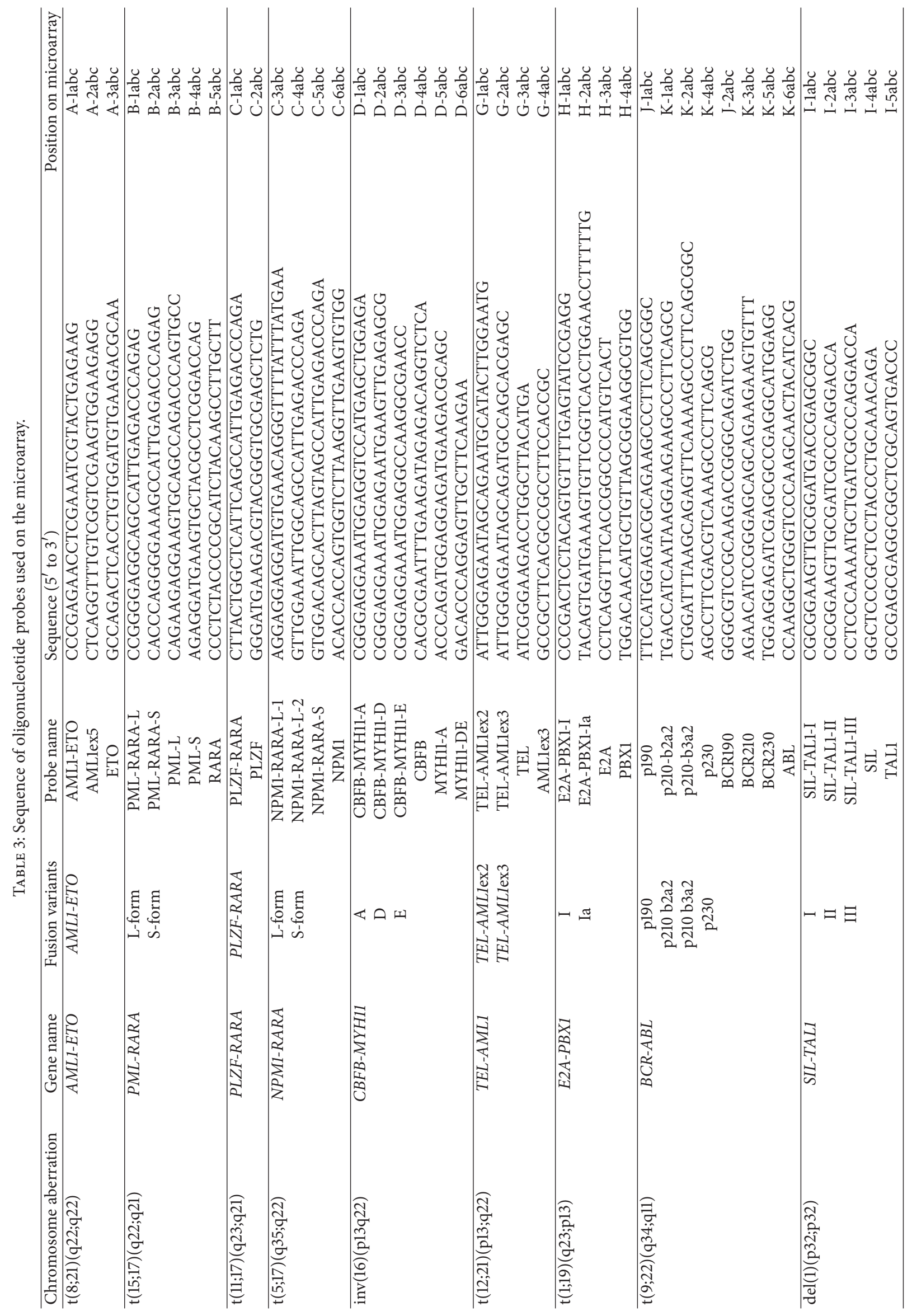




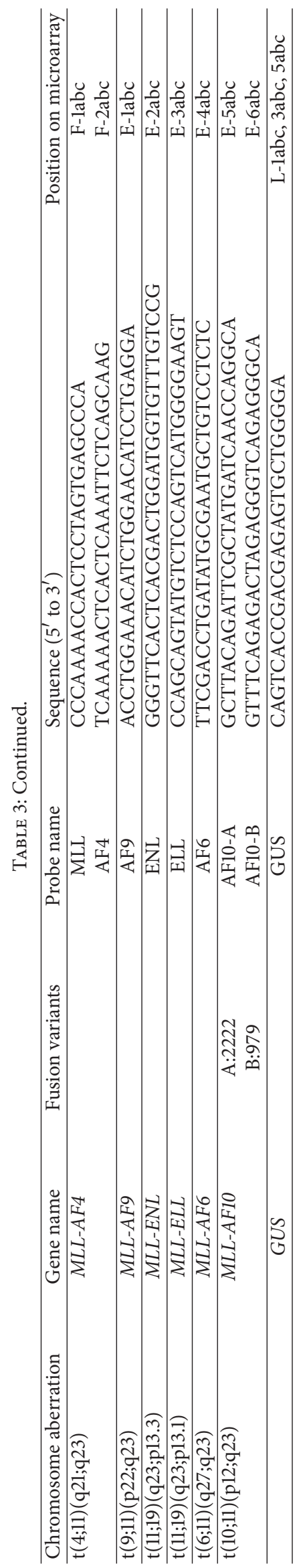




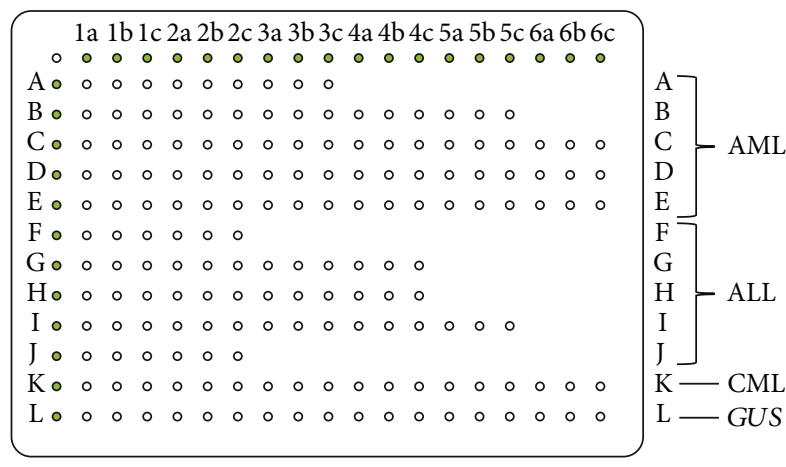

Figure 1: The illustration of the microarray. Left capital letters denoted the rows with specific fusion genes $(\mathrm{A}-\mathrm{K})$, and the chimeric junction probes and specific partner's probes for each fusion gene were marked by the numbers $1 \mathrm{a}, 1 \mathrm{~b}, 1 \mathrm{c}-6 \mathrm{a}, 6 \mathrm{~b}, 6 \mathrm{c}$ in triplicate. Row $\mathrm{L}$ represented the internal positive control GUS gene.

The fusion gene microarray was separated into four parts: acute lymphoblastic leukemia (ALL), acute myelogeneous leukemia (AML), chronic myelogeneous leukemia (CML), and reference control. We used GUS gene as an internal positive control. We divided 15 chromosomal aberrations into three groups: AML, AML1-ETO, PML-RARA and its variant rearrangements ( $P L Z F-R A R A, N P M 1-R A R A), C B F B-$ $M Y H 11$, and $M L L$ rearrangements (MLL-AF9, MLL-ENL, $M L L-E L L, M L L-A F 6$, and MLL-AF10); ALL, MLL-AF4, TELAML1, E2A-PBX1, BCR-ABL p190, and SIL-TAL1; CML, BCR$A B L \mathrm{p} 210$ and $\mathrm{p} 230$. Each fusion gene included one probe for each partner and chimeric junction probes specific for each splice variant already known. The partner's probe was as positive control in each gene fusion event, which located upstream or downstream of the described breakpoint. $M L L$ rearrangements only had each partner's probe. We spotted probes for each fusion gene in horizontal row, first chimeric junction probes then specific partner's probes, with continuous triplicate repeats. The biotinylated control probe was arranged in the top row and left column to position the probes and also to control fluorescence signal hybridization. After incubating in Cy3-SA, the fluorescence signal was detected on certain location.

The signal intensities of every three spotted probes were averaged. By trial and error, we confirmed that for each probe the average signal intensity from negative samples and blank control plus $3 \mathrm{x}$ SD was a background value of this probe. To remove the false positive signals, another standard value is established. We finally chose $15 \%$ of biotinylated control probe signal intensity as the second standard, the cutoff value, through the statistics on over 100 samples. When the signal intensity from hybridization was higher than both two standard values, the background value and cutoff value, we believed the probe as true signal. In addition, when the true signal included one chimeric junction probe and two partner's probes of the same fusion gene group, the result was considered to be positive; on the contrary, the result was considered to be negative.
Furthermore we constructed a series of plasmids for each splice variant of fusion genes studied here for optimizing all the probes. In addition, the microarray was also tested with eighteen control samples (six cell lines, eight patient positive samples, and five constructed fusion fractions) of known genotypes to check the reliability of the results (Figure 3 and Supplementary Figure 1). Figure 3 showed four examples, cell line KASUMI-1 with AML1-ETO, K-562 with BCR-ABL b3a2 splice variant, AML patient with $P M L-R A R A$ S-form, and ALL patient with $E 2 A-P B X 1$ (I), respectively. As could be seen, the signal from the GUS-gene was present in all samples (row L).

To estimate the sensitivity of our approach, a limiting dilution experiment was carried out using positive controls. RNA from all positive controls (six leukemic cells and eight patient samples with unique translocations) was serially diluted in $10^{-1}$ steps up to $10^{-4}$ with RNA from HL-60 cells carrying no translocations. Diluted samples were then used in multiplex RT-PCR, followed by microarray hybridization. For different translocations, the sensitivity assays were detected in the following dilutions: KASUMI-1 $10^{-3}$, NB-4 $10^{-2}$, ME-1 $10^{-2}$, THP-1 $10^{-3}$, REH $10^{-2}$, K-562 $10^{-2}$, AML1ETO $10^{-3}$, PML-RARA (S-form) $10^{-2}$, MLL-AF4 10 ${ }^{-2}, M L L-$ ENL $10^{-2}$, MLL-ELL $10^{-2}$, MLL-AF6 $10^{-3}$, MLL-AF10 10 ${ }^{-3}$, $E 2 A-P B X 110^{-3}$, and $B C R-A B L$ p $19010^{-3}$, which indicated that the multiplex assay might detect 2-20 ng targeted RNA.

We also carried out the precision of our approach. Repeatability was tested by total RNA from one positive cell line K-562 bearing at $(9 ; 22) B C R-A B L$ b3a2 splice variant. The RNA was divided into three parts. Each part of RNA was processed for reverse transcription and multiplex RT-PCR. Finally, the three reaction productions were hybridized onto three individual microarrays. The three hybridization results were identical, positive for the $B C R-A B L$ b3a2 translocation (data not shown). Reproducibility was blindly evaluated by three different operators in three independent experiments using total RNA from cell lines (three positive, Kasumi-1, THP-1, and REH, and one negative, HL-60). The mean reproducibility of operators and experiments was 100 and $100 \%$, respectively (Table 4 ). These repeatability and reproducibility results demonstrated that the multiplex RT-PCR-microarrays method had good intra- and interassay precision.

3.2. Patient Samples Testing. Bone marrow samples from 200 patients (74 AML, 115 ALL, and 11 CML) were analyzed blindly using the multiplex RT-PCR combined with microarrays method. Some examples were showed in Figure 4(a).

In AML patients, $37.8 \%$ chromosomal aberrations were found. Most frequent translocations were $\mathrm{t}(15 ; 17)$ PML-RARA (13.5\%), t(8;21) AML-ETO (10.8\%), and inv(16)(p13q22) CBFB-MYH11 (6.8\%). Among ten patients with $P M L-R A R A$, there were five long (L)-form $(b c r l)$ and four short (S)-form (bcr3) transcripts. It was interesting that the one remaining patient number 57 might be $\mathrm{V}$-form transcript, because of the only two signals of probes PML-L and RARA besides GUS (Figure 4(a), patient number 57). The breakpoint of $P M L$ was located within exon 6 (base 


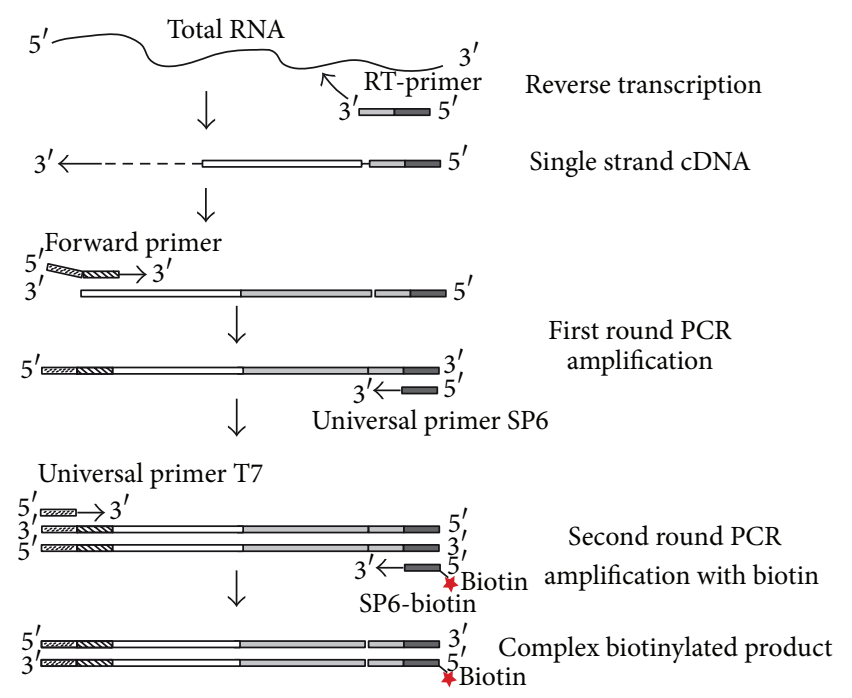

(a)

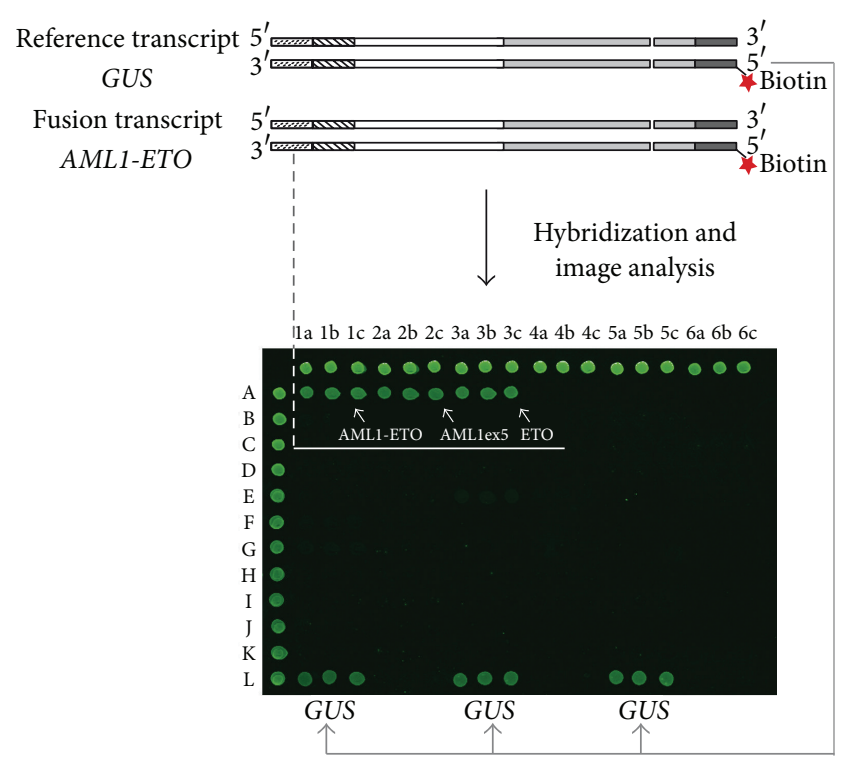

(b)

FIGURE 2: The procedure of multiplex RT-PCR-microarray assay. (a) Steps of multiplex RT-PCR. Reverse transcription was performed on total RNA with multiple chimeric reverse primers. The resulting cDNA was amplified with two-round PCR. First round was amplified with multiple chimeric forward primers on the $5^{\prime}$ region (upstream of known translocation points) and universal primer SP6 on the $3^{\prime}$ region. Second round was with universal primer T7 and biotin labeled SP6, resulting in biotinylated complex. (b) Hybridization with microarray. Take the sample with AML1-ETO translocation as example.

position 1683), belonging to $b c r 2$, which was referred to as "variant" or V-form. Five CBFB-MYH11 patients were all type A, which was consistent with previous findings that type A transcript was the major type in inv(16) positive patients.

In ALL the portion of patients carrying specific translocations was $23.5 \%$. The most frequent translocation was cryptic translocation $\mathrm{t}(12 ; 21)$ TEL-AML1 (15.6\%). In most cases, 15 of 18 patients with TEL-AML1 were found TEL-AML1ex2 variants. Two patients had two variants TEL-AML1ex2 and TEL-AMLlex3 (weaker), owing to alternative splicing causing the skipping of $A M L 1$ exon 2 in a minority of transcripts. The $\mathrm{t}(1 ; 19) E 2 A-P B X 1$ was found in $2.6 \%, \mathrm{t}(4 ; 11) M L L-A F 4$ in $3.4 \%$, and $\mathrm{t}(9 ; 22) B C R-A B L$ p190 in $1.7 \%$.

A relatively large proportion of CML patients were found $\mathrm{t}(9 ; 22) B C R-A B L \mathrm{p} 210$ about $72.7 \%$ including two transcripts with the b3a2 (45.4\%) and b2a2 (27.2\%). Perhaps, the amount of CML patients studied here was only 11, resulting in the fact that the positive portion was lower than expected.

Validation of the multiplex-microarray method was done either by cytogenetics, fluorescence in situ hybridization (FISH), or RT-PCR analysis for all 200 patient samples in the Department of Hematology of Shanghai Children's Medical Center, Ruijin Hospital, Changhai Hospital of Shanghai (Shanghai, China). The detailed information was listed in Supplementary Text 1 and Supplementary Table 1. The comparison of the two methods was shown in Table 5, and the concordance was about $96.5 \%$, except four in AML and three in ALL. It was noted that these seven samples were not involved in the assay. We also performed additional individual PCR reactions for all positive samples (Figure 4(b)). The results of both methods were almost identical.

\section{Discussion}

Monoplex or multiplex RT-PCR techniques have been increasingly used to characterize chromosomal translocations found in leukemic cells, with numerous advantages over traditional cytogenetics and FISH, including shorter turnaround time, no requirement for dividing cells, and detection of cryptic translocations. A multiplex RT-PCR protocol to simultaneously detect 29 translocations had been shown to be effective for clinical screening, followed by series of identifying split-out analysis with primers specific for individual translocations [7]. It was still time- and labor- consuming. Here we facilitated the detection in a single PCR reaction (two rounds), in combination with the following microarrays to simultaneously detect a great variety of different fusion transcripts.

We chose the 15 most frequently occurring and welldefined chromosomal rearrangements in leukemia, covering up to $40-50 \%$ of childhood and adult AML and ALL and 90-95\% of CML patients. These translocations have been regarded as diagnostic and prognostic markers, reflecting risk-stratification and appropriate therapy [16-18]. In general, patients with $\mathrm{t}(12 ; 21) T E L-A M L 1$ fusion and $\mathrm{t}(1 ; 19) E 2 A-P B X 1$ fusion in ALL as well as $\mathrm{t}(8 ; 21)$ AML1-ETO fusion, $\mathrm{t}(15 ; 17)$ $P M L-R A R A$ fusion, and inv(16) CBFB-MYH11 fusion in AML have the most favorable outcome [18-20], whereas those with the $\mathrm{t}(9 ; 22) B C R-A B L$ fusion and $\mathrm{t}(4 ; 11) M L L-A F 4$ fusion in ALL have dismal prognosis $[21,22]$. MLL translocations are usually associated with unfavorable prognosis and poor outcome [23]. However, patients with the MLL-AF9 translocation are clearly associated with a favorable outcome [24]. 

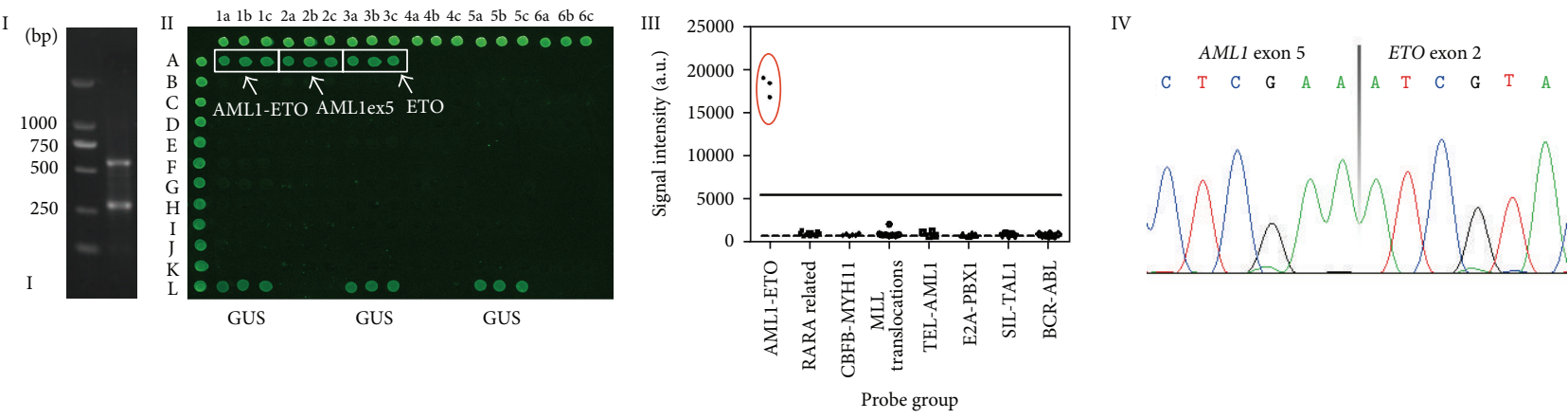

(a) KASUMI-1 AML1-ETO
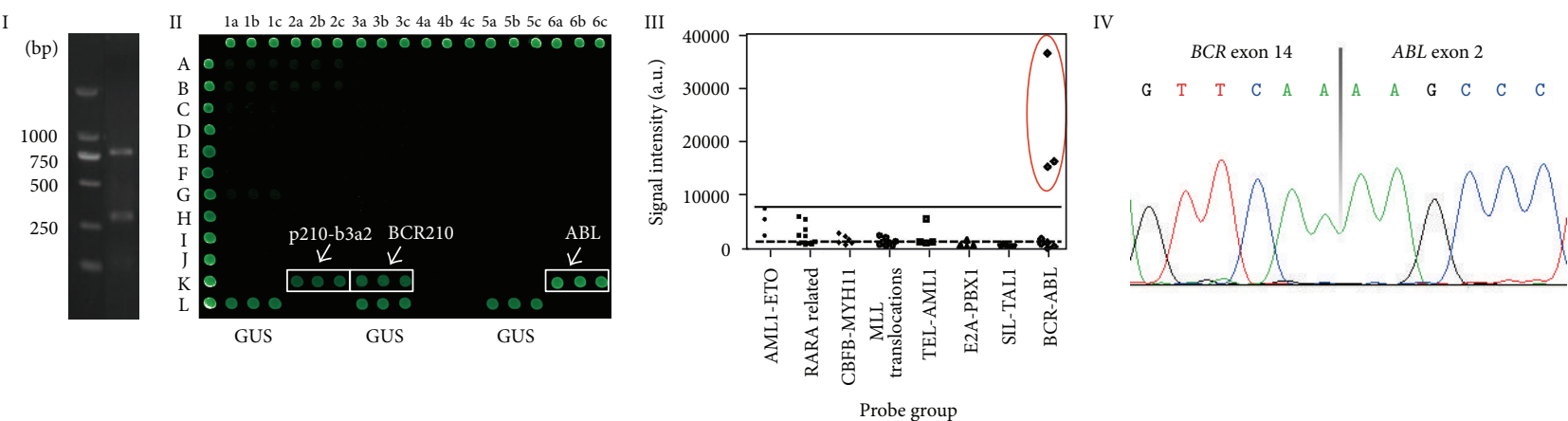

(b) K-562 BCR-ABL p210, b3a2
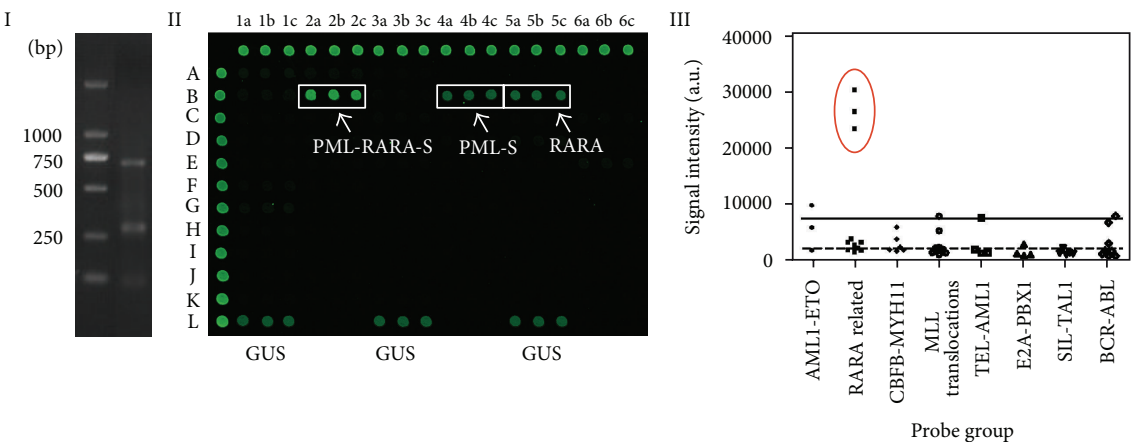

IV

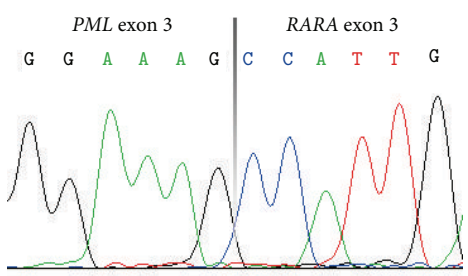

(c) AML patient t(15;17) PML-RARA S-form
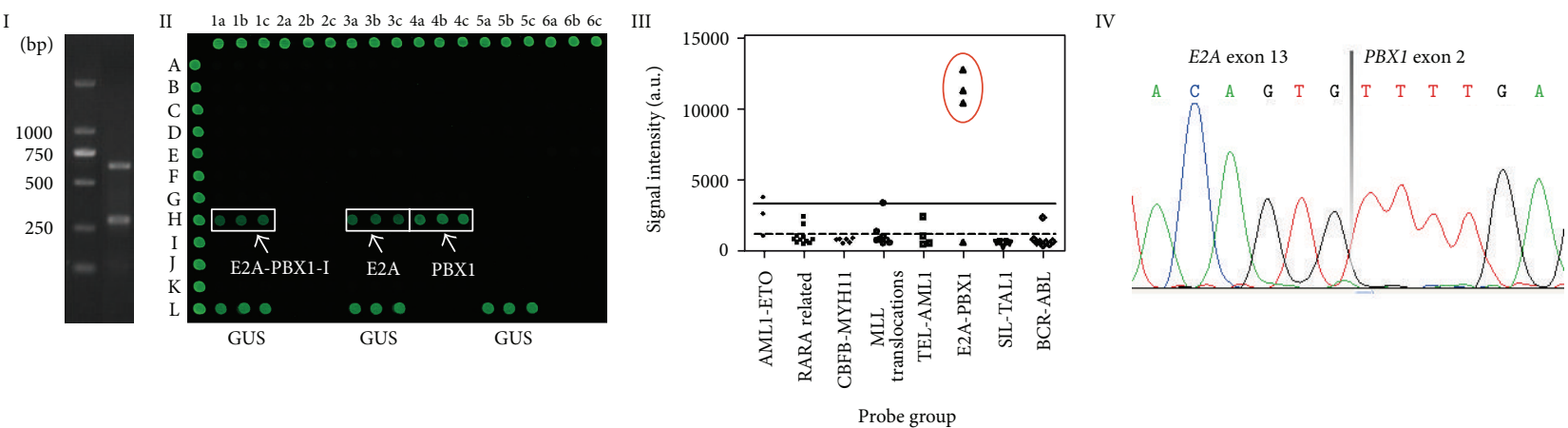

(d) ALL patient t(1;19) E2A-PBX1

FIgURE 3: Results from the multiplex RT-PCR combined with microarray for positive controls. HL-60 and $\mathrm{H}_{2} \mathrm{O}$ were used as negative controls. (a) AML1-ETO in the cell line KASUMI-1. (b) BCR-ABL p210, b3a2 in the cell line K-562. (c) AML patient t(15;17) (PML-RARA) S-form. (d) ALL patient t(1;19) (E2A-PBX1). (I) Multiplex RT-PCR analysis. (II) Microarray analysis. (III) Histogram of data obtained from microarray. The solid line indicated the cutoff value ( $15 \%$ of biotinylated control probe signal intensity). The dashed line indicated the background value (negative samples and blank control plus $3 \mathrm{x}$ SD). Signals over both the cutoff and background control were recognized as true signals (in red circle). (IV) Sequence of multiplex RT-PCR products. 
Patient no. 2

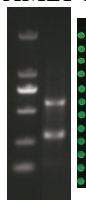

Patient no. 31

MLL-AF9

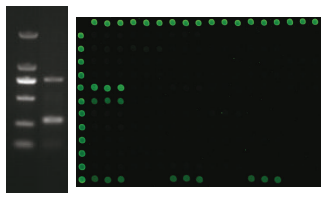

Patient no. 69

MLL-AF6

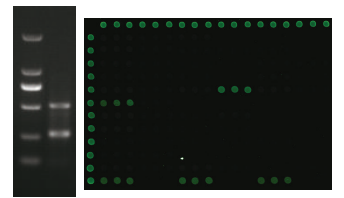

Patient no. 117

BCR-ABL e1-a2
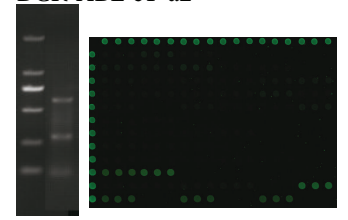

Patient no. 178

E2A-PBX1 (Ia)

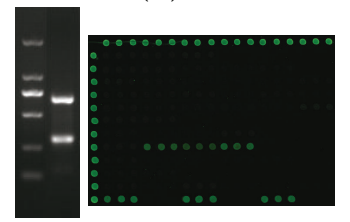

Patient no. 4

PML-RARA L-form
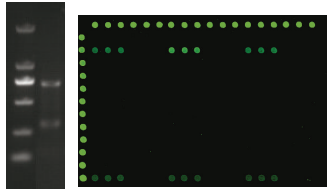

Patient no. 52

$M L L-E N L$

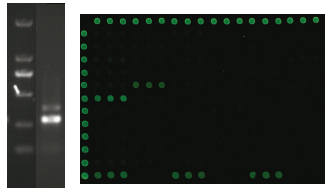

Patient no. 72

MLL-AF10 (B: 979)

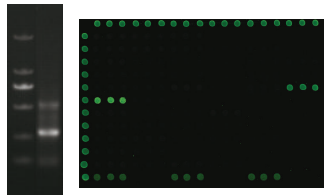

Patient no. 126

E2A-PBX1 (I)

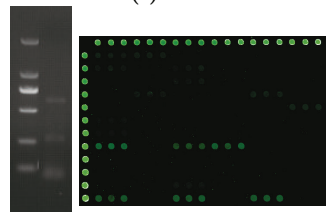

Patient no. 301

$B C R-A B L$ b3a2

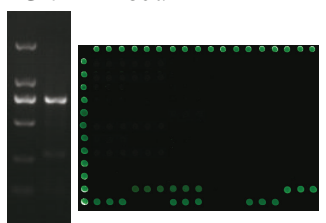

Patient no. 7

CBFB-MYH11 (A)
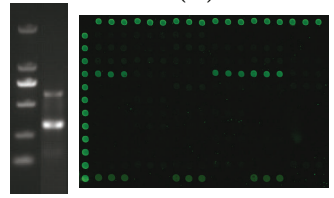

Patient no. 57

PML-RARA V-form

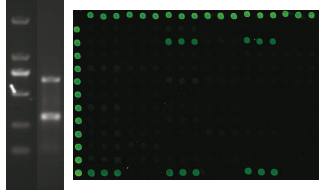

Patient no. 101

TEL-AML1ex2

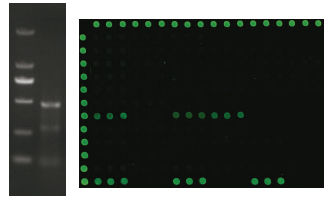

Patient no. 141

TEL-AML1ex2 + ex3
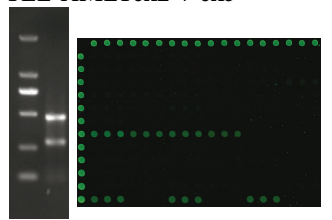

Patient no. 303

$B C R-A B L$ b2a2

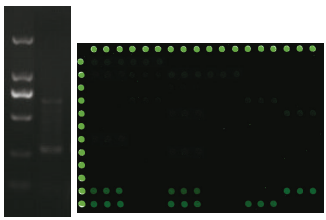

Patient no. 12

PML-RARA S-form

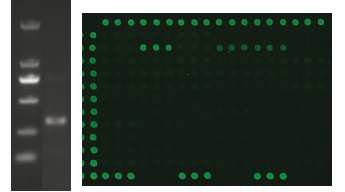

Patient no. 63

MLL-ELL

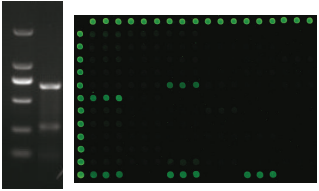

Patient no. 115

MLL-AF4

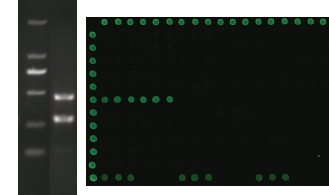

Patient no. 169

TEL-AML1 ex3

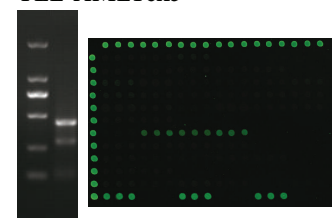

(a)
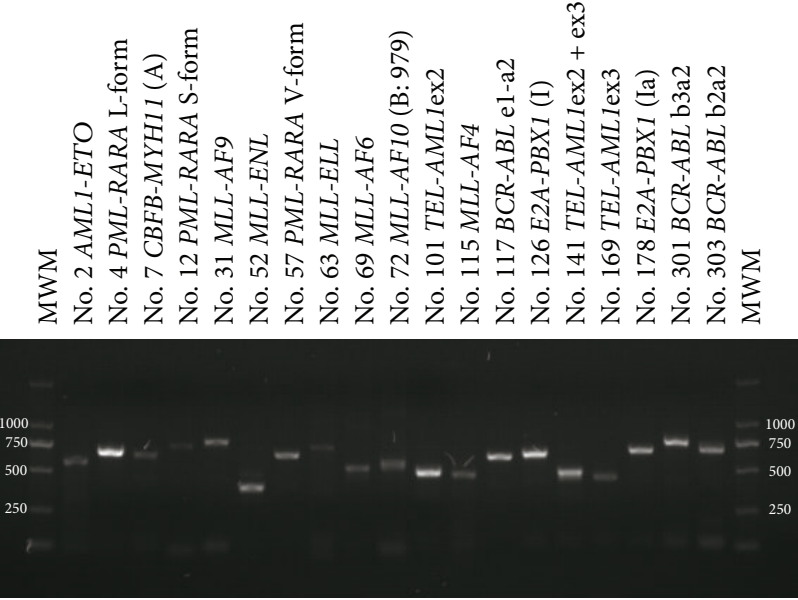

(b)

FiguRE 4: Representative results of fusion genes. (a) Multiplex RT-PCR analysis and the microarray results of 19 clinic samples (10 AML, 7 ALL, and 2 CML). HL-60 and $\mathrm{H}_{2} \mathrm{O}$ were used as negative controls. (b) RT-PCR validation of the microarray positive samples. 
TABLE 4: Reproducibility of operators and experiments.

\begin{tabular}{|c|c|c|c|c|c|}
\hline Operator & RNA & Experiment 1 & Experiment 2 & Experiment 3 & Reproducibility of experiments \\
\hline \multirow{4}{*}{ Operator 1} & Kasumi-1 & AML1-ETO & AML1-ETO & AML1-ETO & \multirow{4}{*}{$100 \%$} \\
\hline & THP-1 & $M L L-A F 9$ & $M L L-A F 9$ & $M L L-A F 9$ & \\
\hline & $\mathrm{REH}$ & TEL-AMLlex2 & TEL-AML1ex2 & TEL-AML1ex2 & \\
\hline & HL-60 & None & None & None & \\
\hline \multirow{4}{*}{ Operator 2} & Kasumi-1 & AML1-ETO & AML1-ETO & AML1-ETO & \multirow{4}{*}{$100 \%$} \\
\hline & THP-1 & $M L L-A F 9$ & $M L L-A F 9$ & $M L L-A F 9$ & \\
\hline & $\mathrm{REH}$ & TEL-AML1ex2 & TEL-AML1ex2 & TEL-AML1ex2 & \\
\hline & HL-60 & None & None & None & \\
\hline \multirow{4}{*}{ Operator 3} & Kasumi-1 & AML1-ETO & AML1-ETO & AML1-ETO & \multirow{4}{*}{$100 \%$} \\
\hline & THP-1 & $M L L-A F 9$ & $M L L-A F 9$ & $M L L-A F 9$ & \\
\hline & $\mathrm{REH}$ & TEL-AML1ex2 & $T E L-A M L 1 \mathrm{ex} 2$ & TEL-AML1ex2 & \\
\hline & HL-60 & None & None & None & \\
\hline \multirow{2}{*}{ Reproducibility of operators } & \multirow{2}{*}{\multicolumn{2}{|c|}{$100 \%$}} & $100 \%$ & $100 \%$ & \\
\hline & & & $100 \%$ & & \\
\hline
\end{tabular}

TABLE 5: Summary of translocations detected by multiplex RT-PCR-microarray method and clinic diagnostic analysis.

\begin{tabular}{|c|c|c|c|c|c|c|}
\hline \multirow{2}{*}{ Translocations } & \multicolumn{3}{|c|}{ Multiplex RT-PCR-microarrays } & \multicolumn{3}{|c|}{ Clinic diagnosis $^{\mathrm{a}}$} \\
\hline & AML & ALL & CML & AML & ALL & CML \\
\hline $\mathrm{t}(8 ; 21)$ AML1-ETO & 8 & & & 8 & & \\
\hline $\mathrm{t}(15 ; 17) P M L-R A R A$ & 10 & & & 10 & & \\
\hline $\operatorname{inv}(16) C B F B-M Y H 11$ & 5 & & & 5 & & \\
\hline $\mathrm{t}(9 ; 11) M L L-A F 9$ & 1 & & & 1 & & \\
\hline $\mathrm{t}(11 ; 19) M L L-E N L$ & 1 & & & 1 & & \\
\hline $\mathrm{t}(11 ; 19) M L L-E L L$ & 1 & & & 1 & & \\
\hline $\mathrm{t}(6 ; 11) M L L-A F 6$ & 1 & & & 1 & & \\
\hline $\mathrm{t}(10 ; 11) M L L-A F 10$ & 1 & & & 1 & & \\
\hline $\mathrm{t}(4 ; 11) M L L-A F 4$ & & 4 & & & 4 & \\
\hline $\mathrm{t}(12 ; 21) T E L-A M L 1$ & & 18 & & & 18 & \\
\hline $\mathrm{t}(1 ; 19) E 2 A-P B X 1$ & & 3 & & & 3 & \\
\hline $\mathrm{t}(9 ; 22) B C R-A B L \mathrm{p} 190$ & & 2 & & & 2 & \\
\hline $\mathrm{t}(9 ; 22) B C R-A B L \mathrm{p} 210$ & & & 8 & & & 8 \\
\hline Other translocations & & & & 4 & 3 & \\
\hline Total number of patients with translocations & 28 & 27 & 8 & 32 & 30 & 8 \\
\hline Total number of patients & 74 & 115 & 11 & 74 & 115 & 11 \\
\hline
\end{tabular}

${ }^{a}$ Clinic diagnosis was carried out by either cytogenetic, FISH, or RT-PCR analysis.

Compared with the previous reports [11-14, 25], the procedure established here had many advantages. First, the procedure here targeted more chromosomal translocations. We focused on about 15 chromosomal translocations, including more than $50 \mathrm{mRNA}$ splice variants. However, the previous reports only had allowed the analysis of only a few rearrangements and one split variant in each fusion gene. For instance, the AMLFusionChip [14] only included three major types of rearrangements in AML: AML1-ETO, CBFB$M Y H 11$, and 11q23/MLL abnormalities (MLL-AF9, MLL-ENL, $M L L-A F 6$, and MLL-AF10); the gel-based biochip developed by Nasedkina et al. [12] addressed 13 fusion variants in 7 leukemia translocations. Second, the range of detection was wider, covering AML, ALL, and CML. AMLFusionChip was only limited to one leukemia group. Third, the operating steps were easier. The assay here used chimeric primers, amplifying different fusion transcripts in the same condition. In previous reports, it was necessary to perform the standard multiplex RT-PCR with multiple parallel nested PCR reactions.

A control gene was also used as an internal control to evaluate the RT-PCR reaction and hybridization process. $A B L, B 2 M$, and GUS were three candidate control genes for multiplex RT-PCR [15]. $A B L$ is a more reliable control gene to compare diagnostic and MRD samples, yet there may be competition between $B C R-A B L$ fusion transcripts and $A B L$ gene when amplifying samples with $\mathrm{t}(9 ; 22)$. However GUS 
gene is also similarly expressed in normal and diagnostic samples, and variation of GUS and fusion gene transcript expression are correlated. Based on these, we chose GUS as control gene in this study.

We also tested the sensitivity of positive controls. It was the fact that the sensitivity was weak in multiplex RT-PCR compared to single PCR reactions, especially for detection of minimal residual diseases. We could observe in this report that the sensitivity of our reactions was decreased one to two orders of magnitude, due to the existence of sixteen primers in first reaction round. However, in incipient patient diagnosed with leukemia, the cell source used for RNA preparations was usually greater than $90 \%$ leukemic blasts. Moreover, the use of microarrays could improve the efficiency of discriminating splice variants and minimize the risk of contamination. Thus this multiplex PCR-microarray assay was suitable for diagnosing de novo leukemia.

We had scaled up in this method of analysis 200 patients with 74 AML, 115 ALL, and 11 CML. In 6 AML and 9 ALL cases, the internal control band using multiplex-microarray could not be detected. This could be ascribed to insufficient amount or quantity of RNA. Four in AML and 3 in ALL samples were beyond the detection scope of the assay. With regard to AML, $\mathrm{t}(15 ; 17) P M L-R A R A, \mathrm{t}(8 ; 21) A M L-E T O$ and inv(16)(p13q22)CBFB-MYH11 were mainly identified. In ALL, $\mathrm{t}(12,21) T E L-A M L 1$ was predominantly observed, while $\mathrm{t}(4,11) M L L-A F 4, \mathrm{t}(1,19) E 2 A-P B X 1$, and $\mathrm{t}(9,22) B C R-A B L \mathrm{p} 190$ were less frequently identified. Two forms of $B C R-A B L \mathrm{p} 210$ in CML were found: $\mathrm{b} 3 \mathrm{a} 2$ and $\mathrm{b} 2 \mathrm{a} 2$ transcripts, and the proportion of $\mathrm{b} 3 \mathrm{a} 2$ was a little higher than that of $\mathrm{b} 2 \mathrm{a} 2$. The majority of splice variants in $P M L-R A R A, E 2 A-P B X 1$, and TEL-AML1 were PML-RARA L-form (50\%), E2A-PBX1 (I) (66.7\%), and TEL-AML1ex2 (94.4\%), respectively. In addition, we also detected a novel form of $P M L-R A R A$, besides Lform and $\mathrm{S}$-form transcripts, classified as $\mathrm{V}$-form transcripts. The statistics on the frequency of different splice variants might provide more profound and additional molecular characteristics of the majority fusion transcripts styles. This would eventually allow a more precise clinical diagnosis and optimization of therapy.

The multiplex PCR-microarray assay could also be applied to detect rare rearrangements, such as PLZF-RARA, NPM1-RARA, and SIL-TAL1. For CBFB-MYH11 translocation, type A transcript accounted for more than $85 \%$ of the positive patients; two other transcripts ( $D$ and $E$ ) represented nearly $5 \%$ each, whereas all others represented unique cases [4]. We designed two reverse primers and MYH11 probes for type A and types D and E, respectively. It was indicated that there were other seven or novel transcripts though signal intensity of wild probes CBFB, MYH11-A, and MYH11-DE.

The rare chromosomal rearrangements, such as $\mathrm{t}(6 ; 9) D E K-C A N, \mathrm{t}(17 ; 19) E 2 A-H L F, \mathrm{t}(16 ; 21) T S L-E R G$, and $\mathrm{t}(3 ; 21) A M L 1-M D S 1-(E V I 1)$, and other $M L L$ rearrangements were also worth adding the present pipeline. Although there was no independent prognostic significance, these aberrations could be very important in screening the potential chromosomal rearrangements.

\section{Conflict of Interests}

The authors declare that they have no conflict of interests.

\section{Acknowledgments}

This work was supported by Shanghai Science and Technology Committee (Grant no. 08411953800) and Shanghai Municipal Education Commission (Grant no. 2010Z14180026). The authors thank Dr. Chun-Lei Jiang, Qiu-Hua Huang, and Sai-Juan Chen for providing the leukemia cell lines and clinical patients and diagnosing the samples.

\section{References}

[1] J. W. Vardiman, N. L. Harris, and R. D. Brunning, "The World Health Organization (WHO) classification of the myeloid neoplasms," Blood, vol. 100, no. 7, pp. 2292-2302, 2002.

[2] J. W. Vardiman, J. Thiele, D. A. Arber et al., "The 2008 revision of the World Health Organization (WHO) classification of myeloid neoplasms and acute leukemia: rationale and important changes," Blood, vol. 114, no. 5, pp. 937-951, 2009.

[3] A. T. Look, "Oncogenic transcription factors in the human acute leukemias," Science, vol. 278, no. 5340, pp. 1059-1064, 1997.

[4] J. Gabert, E. Beillard, V. H. J. van der Velden et al., "Standardization and quality control studies of 'real time' quantitative reverse transcriptase polymerase chain reaction of fusion gene transcripts for residual disease detection in leukemia-a Europe Against Cancer Program," Leukemia, vol. 17, no. 12, pp. 23182357, 2003.

[5] P. Raanani and I. Ben-Bassat, "Detection of minimal residual disease in acute myelogenous leukemia," Acta Haematologica, vol. 112, no. 1-2, pp. 40-54, 2004.

[6] C.-H. Pui, M. V. Relling, and J. R. Downing, "Mechanisms of disease: acute lymphoblastic leukemia," The New England Journal of Medicine, vol. 350, no. 15, pp. 1535-1548, 2004.

[7] N. Pallisgaard, P. Hokland, D. C. Riishøj, B. Pedersen, and P. Jørgensen, "Multiplex reverse transcription-polymerase chain reaction for simultaneous screening of 29 translocations and chromosomal aberrations in acute leukemia," Blood, vol. 92, no. 2, pp. 574-588, 1998.

[8] M. Salto-Tellez, S. G. Shelat, B. Benoit et al., "Multiplex RTPCR for the detection of leukemia-associated translocations: validation and application to routine molecular diagnostic practice," Journal of Molecular Diagnostics, vol. 5, no. 4, pp. 231236, 2003.

[9] R. L. King, M. Naghashpour, C. D. Watt, J. J. D. Morrissette, and A. Bagg, "A comparative analysis of molecular genetic and conventional cytogenetic detection of diagnostically important translocations in more than 400 cases of acute leukemia, highlighting the frequency of false-negative conventional cytogenetics," American Journal of Clinical Pathology, vol. 135, no. 6, pp. 921-928, 2011.

[10] J. Wallace, Y. Zhou, G. N. Usmani et al., "BARCODE-ALL: accelerated and cost-effective genetic risk stratification in acute leukemia using spectrally addressable liquid bead microarrays," Leukemia, vol. 17, no. 7, pp. 1411-1413, 2003.

[11] T. Nasedkina, P. Domer, V. Zharinov, J. Hoberg, Y. Lysov, and A. Mirzabekov, "Identification of chromosomal translocations in 
leukemias by hybridization with oligonucleotide microarrays," Haematologica, vol. 87, no. 4, pp. 363-372, 2002.

[12] T. V. Nasedkina, V. S. Zharinov, E. A. Isaeva et al., "Clinical Screening of Gene Rearrangements in Childhood Leukemia by Using a Multiplex Polymerase Chain Reaction-Microarray Approach," Clinical Cancer Research, vol. 9, no. 15, pp. 56205629, 2003.

[13] N. Maroc, A. Morel, E. Beillard et al., "A diagnostic biochip for the comprehensive analysis of MLL translocations in acute leukemia," Leukemia, vol. 18, no. 9, pp. 1522-1530, 2004.

[14] S. Giusiano, C. Formisano-Treziny, A. Benziane et al., "Development of a biochip-based assay integrated in a global strategy for identification of fusion transcripts in acute myeloid leukemia: a work flow for acute myeloid leukemia diagnosis," International Journal of Laboratory Hematology, vol. 32, no. 4, pp. 398-409, 2010.

[15] E. Beillard, N. Pallisgaard, V. H. J. van der Velden et al., "Evaluation of candidate control genes for diagnosis and residual disease detection in leukemic patients using 'real-time' quantitative reverse-transcriptase polymerase chain reaction (RQ-PCR)—a Europe against cancer program," Leukemia, vol. 17, no. 12, pp. 2474-2486, 2003.

[16] C.-H. Pui, L. L. Robison, and A. T. Look, "Acute lymphoblastic leukaemia," The Lancet, vol. 371, no. 9617, pp. 1030-1043, 2008.

[17] M. Aricò, M. G. Valsecchi, B. Camitta et al., "Outcome of treatment in children with Philadelphia chromosome-positive acute lymphoblastic leukemia," The New England Journal of Medicine, vol. 342, no. 14, pp. 998-1006, 2000.

[18] D. Grimwade and R. K. Hills, "Independent prognostic factors for AML outcome," Hematology, pp. 385-395, 2009.

[19] S. E. Aspland, H. H. Bendall, and C. Murre, "The role of E2APBX1 in leukemogenesis," Oncogene, vol. 20, no. 40, pp. 57085717, 2001.

[20] C.-H. Pui, J. M. Boyett, G. K. Rivera et al., "Long-term results of total therapy studies 11, 12 and $13 \mathrm{~A}$ for childhood acute lymphoblastic leukemia at St Jude children's research hospital," Leukemia, vol. 14, no. 12, pp. 2286-2294, 2000.

[21] M. Schrappe, M. Aricò, J. Harbott et al., "Philadelphia chromosome-positive $(\mathrm{Ph}+)$ childhood acute lymphoblastic leukemia: good initial steroid response allows early prediction of a favorable treatment outcome," Blood, vol. 92, no. 8, pp. 2730-2741, 1998.

[22] C.-H. Pui, P. S. Gaynon, J. M. Boyett et al., "Outcome of treatment in childhood acute lymphoblastic leukaemia with rearrangements of the 11q23 chromosomal region," The Lancet, vol. 359, no. 9321, pp. 1909-1915, 2002.

[23] J. B. Nachman, N. A. Heerema, H. Sather et al., "Outcome of treatment in children with hypodiploid acute lymphoblastic leukemia," Blood, vol. 110, no. 4, pp. 1112-1115, 2007.

[24] J. E. Rubnitz, S. C. Raimondi, X. Tong et al., "Favorable impact of the $\mathrm{t}(9 ; 11)$ in childhood acute myeloid leukemia," Journal of Clinical Oncology, vol. 20, no. 9, pp. 2302-2309, 2002.

[25] R. Z. Shi, J. M. Morrissey, and J. D. Rowley, "Screening and quantification of multiple chromosome translocations in human leukemia," Clinical Chemistry, vol. 49, no. 7, pp. 10661073, 2003. 


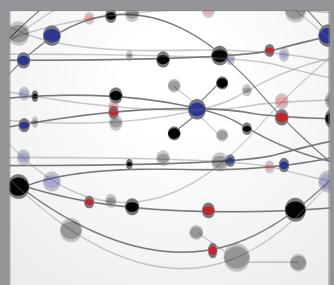

The Scientific World Journal
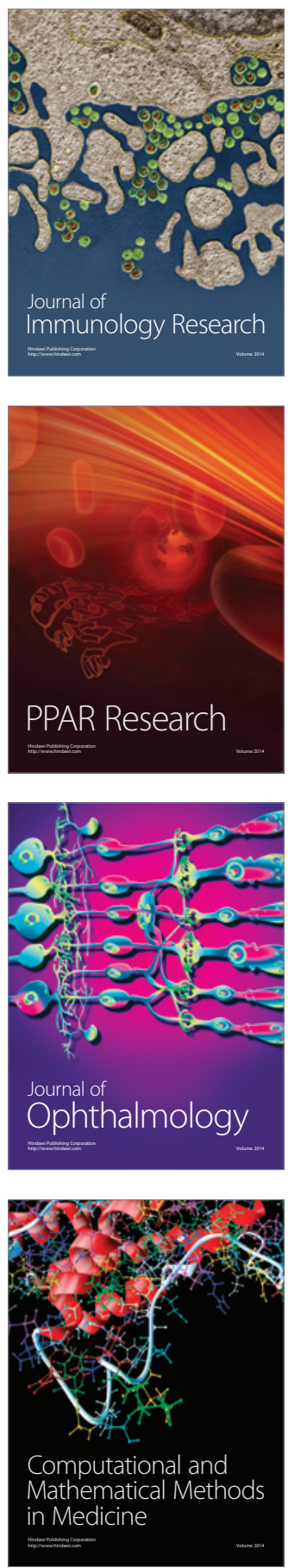

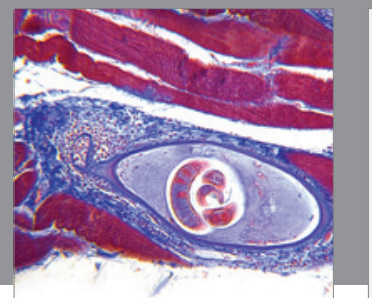

Gastroenterology

Research and Practice
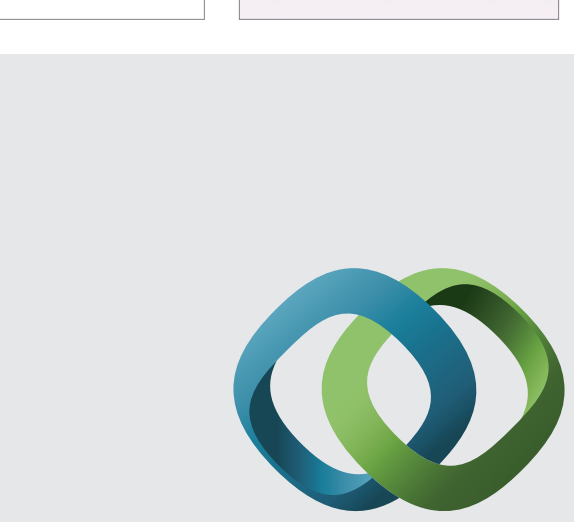

\section{Hindawi}

Submit your manuscripts at

http://www.hindawi.com
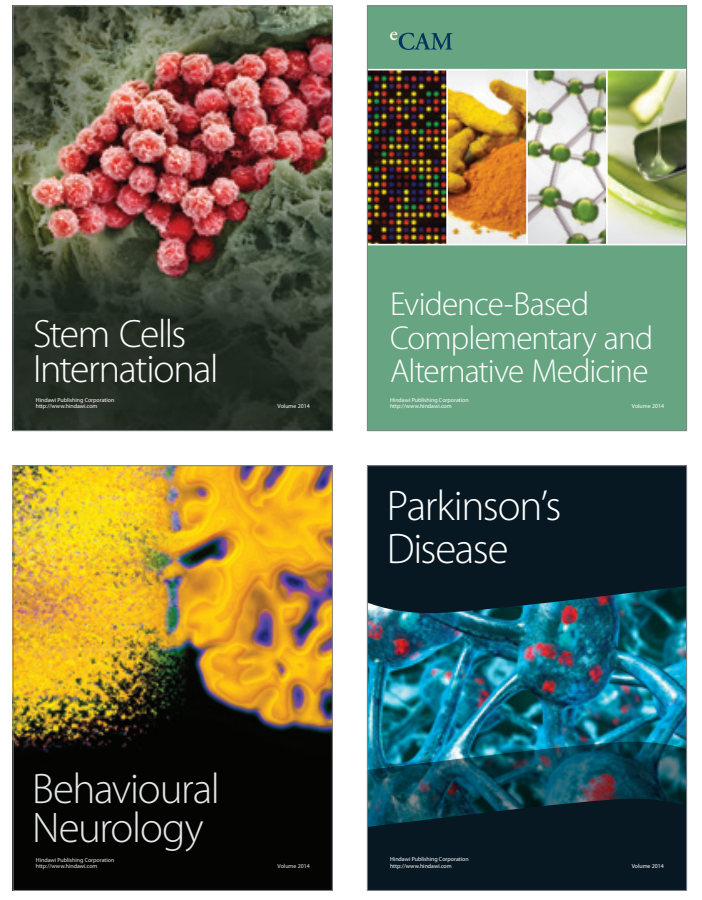
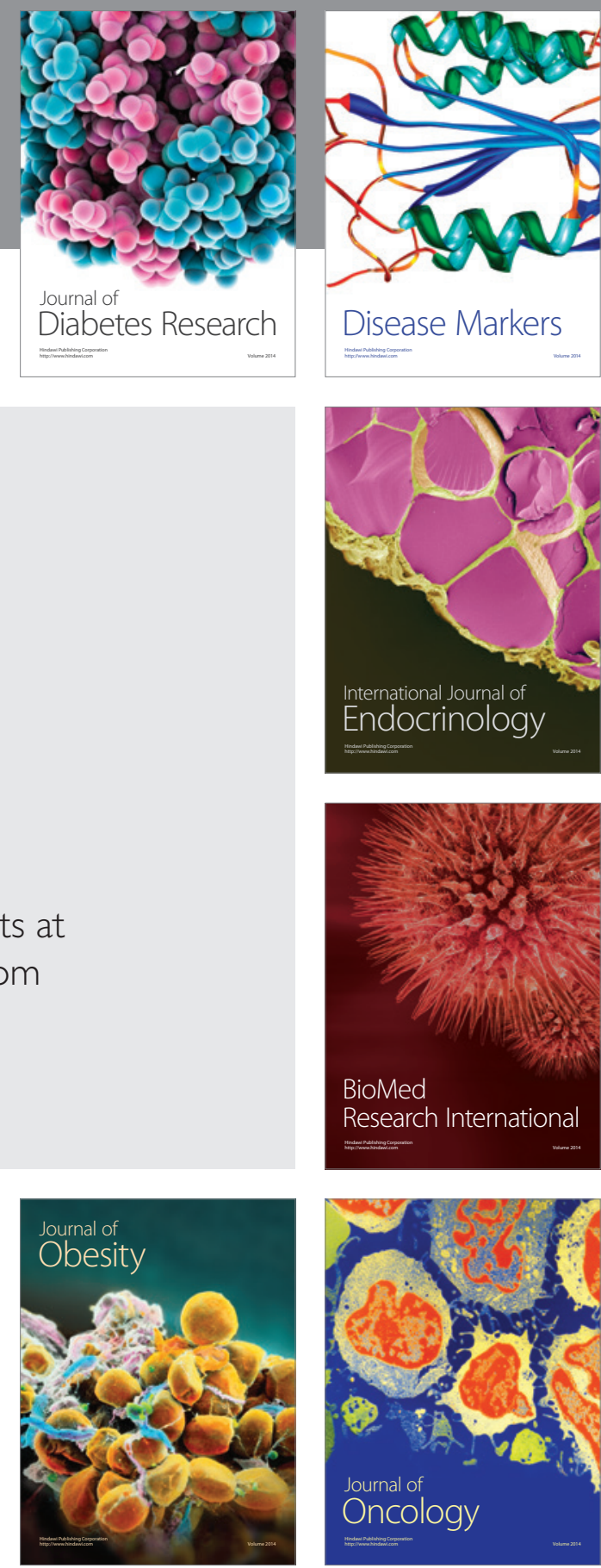

Disease Markers
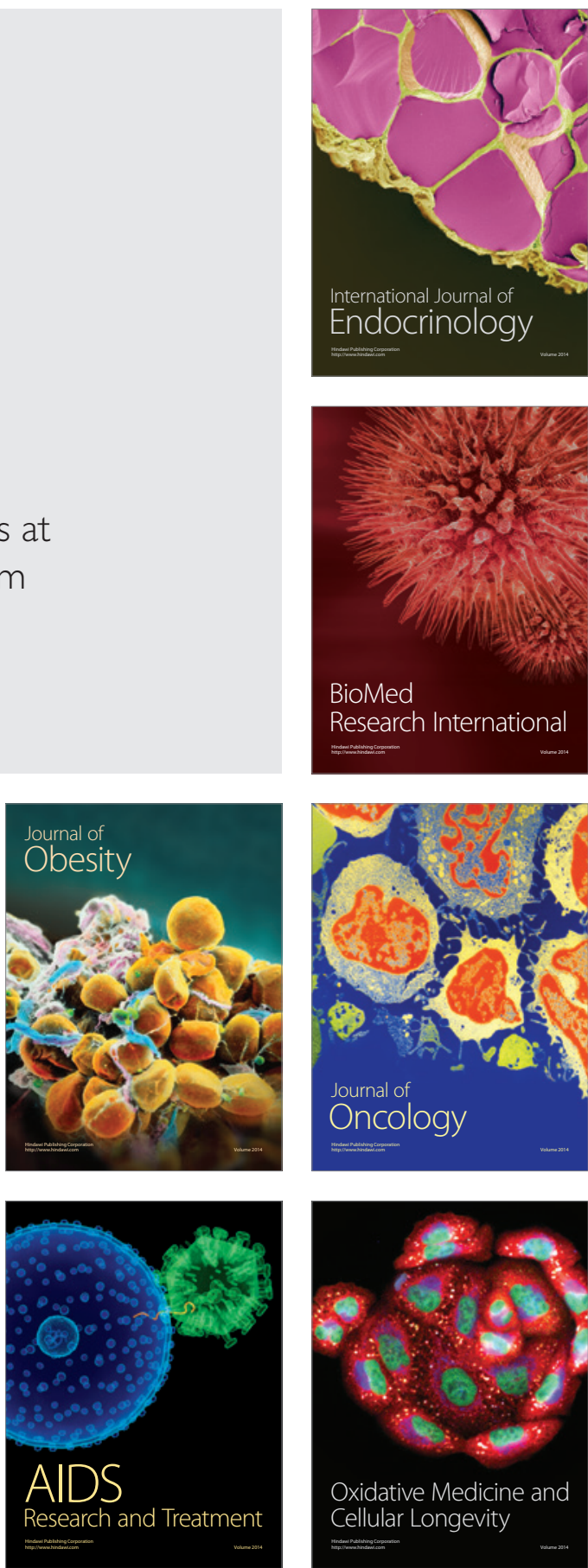